\title{
Mechanistic Study of Phosphorus Adsorption onto Iron Z-A: Spectroscopic and Experimental Approach
}

\author{
Md Saifuddin ${ }^{1,2}$, Suho Kim ${ }^{1,2}$, Abdul Aziz ${ }^{3}$ and Kwang Soo Kim ${ }^{1,2, *}$ \\ 1 University of Science and Technology (UST) Korea, 217 Gajeong-ro, Yuseong-gu, Daejeon 34113, Korea; \\ saifuddin@kict.re.kr (M.S.); kimsuho@kict.re.kr (S.K.) \\ 2 Department of Land, Water, and Environment Research, Korea Institute of Civil Engineering and Building \\ Technology (KICT), Gyeonggi-do, Goyang-si 10223, Korea \\ 3 Chemistry Control Division C-2, Pakistan Atomic Energy Commission (PAEC), Islamabad 1114, Pakistan; \\ aziz1ctn@gmail.com \\ * Correspondence: kskim@kict.re.kr; Tel.: +82-31-910-0299 or +82-10-9096-9102
}

Received: 30 September 2019; Accepted: 4 November 2019; Published: 15 November 2019

Featured Application: Authors are encouraged to provide a concise description of the specific application or a potential application of the work. This section is not mandatory.

\begin{abstract}
Iron was incorporated into an LTA type zeolite using the sol-gel hydrothermal method to form Iron-zeolite-A (Iron-Z-A), and its phosphate adsorption-desorption efficiency were analyzed. Samples were characterized by EDS, SEM, XRD, EPR, FT-IR XPS, and Raman to ensure the apt synthesis of Iron-Z-A and to interpret the mechanism of adsorption-desorption of $\mathrm{PO}_{4}{ }^{3-}$ in an aqueous solution. EPR and XPS analysis confirmed that the iron was doped as $\mathrm{Fe} 3+$ in the LTA structure. The XPS peak shift (Fe-2p), FT-IR band shift, and intensity change $(-\mathrm{OH})$ confirmed the existence of the ligand exchange mechanism. In the adsorption phase at $\mathrm{pH} 5$, the derivative of phosphate $\left(\mathrm{H}_{2} \mathrm{PO}_{4}{ }^{-}\right)$acts as a ligand and interacts with $\mathrm{OH}$ of $\mathrm{Fe}$ on the zeolite surface to form "Iron-zeolite (oxy) hydroxide bound phosphate". In the desorption phase at $\mathrm{pH} 10$, phosphate ligand is detached and get mixed in the aqueous phase as $\mathrm{HPO}_{4}{ }^{2-}$. The EDS data, $\mathrm{Si}-\mathrm{O}-\mathrm{Al}$ band shift and intensity change in FT-IR and XPS peak intensity change proved the contribution of $\mathrm{Al}$ in the process of adsorption. The data of adsorption fitted well with the Langmuir's isotherm and pseudo-second-order kinetic model. The amount of $\mathrm{PO}_{4}{ }^{3-}$ adsorbed was a function of adsorbent's surface area regardless of concentration. The amount of $\mathrm{PO}_{4}{ }^{3-}$ being adsorbed by the metal ions was found to be $382.296 \mathrm{mg}$ $\mathrm{PO}_{4}{ }^{3-} / \mathrm{g}$ Fe and $56.296 \mathrm{mg} \mathrm{PO}_{4}{ }^{3-} / \mathrm{g} \mathrm{Al}$.
\end{abstract}

Keywords: Iron; zeolite-A; phosphate; adsorption-desorption; mechanism; kinetics

\section{Introduction}

Across the globe, imperil to pollution of water bodies is very high due to anthropogenic activities. Stringent norms and legislations have been passed in many countries to overcome or slow down the disposal of pollutants into the water system [1]. Lack of excellent water resources has propelled the treatment of wastewater to reuse for the sustainable exploitation of this natural resource [2].

Phosphorous is one of the principal elements required for the growth of animals and plants. It forms the backbone of the DNA as well as Kreb's cycle, and it plays a crucial role as a growth-limiting nutrient. In aqueous medium, ' $\mathrm{P}$ ' resides in the form of organic phosphorus, polyphosphate, and, an organophosphate. Only orthophosphate can be easily taken up by algae and most of the plants. By microbial immobilization or hydrolysis, organic phosphorous and polyphosphates transform into orthophosphate [3]. Cleaning and detergent products also contain $\mathrm{P}$ in the form of 
tripolyphosphate, which eventually gets converted to orthophosphate [4]. As there is a change in the $\mathrm{pH}$ values of the aqueous solution in agreement with their $\mathrm{pK}$ values, the ionic charge, and chemical form of orthophosphate keep on changing $[3,5,6]$. So the $\mathrm{pH}$ change tends to stimulate P's physicochemical functions in water. Excessive input of phosphorous or orthophosphate can lead to a massive fluctuation in the quality of water in a lake and trophic status. In many of the cases, it causes cyanobacterial periodic bloom [7-9]. A surplus amount of this nutrient in water causes eutrophication [10-12], which can harshly affect the ecological balance in a water system [13].

So far, many techniques have been introduced by various researchers in this field to effectively eliminate phosphate from an aqueous solution, like precipitation and floatation [14], enzymatic biodegradation [15], electrochemistry [16], and adsorption [17]. From all these techniques, adsorption is one of the extensively used technique for the elimination of phosphates from the water. It is a very simple, low cost, fast, and environmentally safe process $[18,19]$. Conventionally, activated charcoal $[20,21]$ and porous silica materials $[22,23]$ are being used to remove phosphate from contaminated water. Adsorption is one of the widely used methods to remove phosphate from aqueous solution. The most researched adsorbing materials have the following $\mathrm{P}$ maximum adsorption capacity in terms of $\mathrm{mg}$ of $\mathrm{P}$ adsorbed/g of adorbent; fly ash at $\mathrm{pH} 11-12-30-36 \mathrm{mg} \mathrm{P} / \mathrm{g}$ [24], alum sludge at $\mathrm{pH} 4-32 \mathrm{mg} \mathrm{P} / \mathrm{g}$ [25], alumina at $\mathrm{pH} 5.5-14 \mathrm{mg} \mathrm{P} / \mathrm{g}$ [26], basic oxygen furnace slag at $\mathrm{pH} 7-7.2-20 \mathrm{mg} \mathrm{P} / \mathrm{g} \mathrm{[27],} 700{ }^{\circ} \mathrm{C}$ heated red mud-113 mg P/g [28], activated carbon at $\mathrm{pH} 4-3.2 \mathrm{mg} \mathrm{P} / \mathrm{g}$ [29] as activated carbon is hydrophobic in nature. Activated alumina, silica sand, and anthracite coal exhibited $3333 \mu \mathrm{g} / \mathrm{g}, 49 \mu \mathrm{g} / \mathrm{g}$, and $100 \mu \mathrm{g} / \mathrm{g}$, respectively [30].

Zeolites are well-defined three-dimensional structures. They form crystalline and microporous solids bearing silicon, aluminum, and oxygen in its framework, whereas water and cations are situated in the pores. Zeolites are naturally occurring materials as well as it is synthesized industrially. About 245 types of zeolite structures have been identified so far, and among which, forty of the zeolite structures are naturally occurring $[31,32]$. The silica to alumina ratio for synthetic and natural zeolites is 5:1 and 1:1, respectively. The natural zeolite structures are more resistant to the acidic environment than synthetic zeolites; hence, it is easily used in the agricultural sector [33]. Synthetic zeolite is extensively used in numerous industrial applications because of its unique structure and properties. Zeolite-A manifests Linde Type-A (LTA) structure, which has a 3D pore structure with pores that are perpendicular to one another. Zeolite has technological and scientific value due to its interacting ability with different molecules and ions in the inner pores as well as outer surfaces [34]. Elimination of phosphate from water can be done using various forms of iron, such as sponge iron, goethite, akaganeite, and iron ore. These iron-based adsorbents showed high phosphate adsorption capabilities, but have a longer removal time and hydraulic retention time. In the case of sponge iron, it showed $90 \%$ phosphate removal in $12 \mathrm{~h} \mathrm{[35],} \mathrm{and} \mathrm{iron} \mathrm{ore} \mathrm{showed} 97 \%$ phosphate removal in 15 days [36]. Synthetic goethite has $40-100 \%$ phosphate removal capacity, but it takes $2-8 \mathrm{~h}$. Likewise, akaganeite showed $15-100 \%$ removal efficiency in $4-8 \mathrm{~h}$ [37]. Biogenic iron oxide exhibited $100 \%$ removal, but the time required was $24 \mathrm{~h}$ [38]. Many research teams tried to resolve this problem by using different iron sources. Aziz et al. (2016) [39], synthesized Iron-ZSM-5 material in which the iron source was AIC (ammonium iron citrate). It possessed regenerative properties which have potential application in wastewater treatment and catalysis. Because of the sharp reduction in the available phosphorus resource, both phosphorus removal and recovery are considered in the wastewater treatment process [40]. Unfortunately, very few studies have achieved to handle this issue. In addition, there is a lack of adequate research on the mechanism of phosphate adsorption-desorption by zeolite. In the current work, we conducted a phosphate adsorption-desorption cycle experiment and focused on the first adsorption-desorption cycle and tried to analyze the activity of different elements of Iron-Zeolite-A (Iron-Z-A) with respect to phosphate. Spectroscopic and microscopic techniques such as XRD, SEM-EDS, EPR, FT-IR, XPS, and Raman were used to explain the prime mechanism behind adsorption-desorption of phosphate vividly. Kinetics and isotherm models were performed to evaluate the performance of adsorption-desorption. 


\section{Materials and Methods}

\subsection{Synthesis of Adsorbents}

Synthesis of Z-A (Zeolite-A) and Iron-Z-A (Iron-Zeolite-A) was performed by the Sol-Gel method. It was carried in a hydrothermal reactor. Sodium silicate $\left(\mathrm{Na}_{2} \mathrm{SiO}_{3}\right.$, Sigma Aldrich, St. Louis, Missouri, United States) and sodium aluminate $\left(\mathrm{NaAlO}_{2} ; 37-45 \% \mathrm{Na}_{2} \mathrm{O}, 50-56 \% \mathrm{Al}_{2} \mathrm{O}_{3}\right.$; Sigma Aldrich St. Louis, Missouri, United States) were used as silica and alumina source, respectively. About $170 \mathrm{~mL}$ of distilled water were taken in two separate beakers. One was dissolved with $8.89 \mathrm{~g}$ of $\mathrm{NaAlO}_{2}$ and the other with $11.46 \mathrm{~g}$ and $\mathrm{Na}_{2} \mathrm{SiO}_{3}$. The sodium aluminate solution was mixed to the sodium silicate solution while stirring continuously. The mixed gel was kept for aging in an incubator at room temperature incubator for one day. The mixed gel was then kept for synthesis in a hydrothermal reactor for two days at $120^{\circ} \mathrm{C}$. Then, it was properly washed with distilled water to reduce the filtrate $\mathrm{pH}$ from alkaline to neutral. Lastly, the filtrate samples it was dehydrated at $100{ }^{\circ} \mathrm{C}$ overnight.

In the case of Iron-Z-A, the iron source was AIC (ammonium iron citrate) (Sigma Aldrich, St. Louis, Missouri, United States; Fe 17.5\%). Here, the gel mixture was the same as that of Z-A, but it also consisted of AIC (1.5023 g). Sodium aluminate solution and AIC solution were prepared in two different beakers. Sodium silicate solution was stirred continuously, while AIC and sodium aluminate solution was added to it dropwise separately. Then it followed the same method as Z-A for aging, synthesis, washing, and drying. Finally, the material was calcined for $5 \mathrm{~h}$ at $550{ }^{\circ} \mathrm{C}$ to remove citrate or organic compounds [41,42].

\subsection{Characterization of the Zeolites}

Rigaku D/Max-2500 X-ray diffractometer was used to get the X-ray Powder Diffraction (XRD) peaks of the zeolite materials. It was equipped with $\mathrm{Cu} \mathrm{K} \alpha$ and a Ni filter from 5-50 in $2 \theta$ range. The scanning speed was at $5 \% \mathrm{~min}$. A scanning electron microscope (SEM, Hitachi S-4800, Tokyo, Japan) was used to observe the zeolite's morphology. Energy-dispersive X-ray spectroscopy (EDS, EDX S-10, Oxford, UK) was fitted to it to detect the specific X-ray radiation). The measurement of electron paramagnetic resonance (EPR) spectra was done by JOEL JES-FE1C X-band spectrometer. FT-IR spectra were obtained by analyzing it in the FT-IR spectrometer (Bruker VERTEX 80V, Massachusetts, United States) in a spectral range of $400-4000 \mathrm{~cm}^{-1}$ and $1 \mathrm{~cm}^{-1}$ resolution. The X-ray photoelectron spectroscopy (XPS) peaks were obtained under Al K $\alpha$ X-ray source (Kratos Axis Ultra, Manchester, UK). The test chamber's background pressure was kept under $1.33 \times 10^{-7} \mathrm{~Pa}$. A single-beam spectrometer having 60 added scans with a resolution of $0.02 \mathrm{~m}^{-1}$ was used. The above characterization techniques were used in order to assure proper synthesis and observe the modifications in the parameters of the zeolite samples. A Raman microspectrometer (XploRA, Horiba Jobin Yvon, Horiba-Scientific, Kyoto, Japan) having a 100× and numerical aperture objective (Olympus, Tokyo, Japan) was used to record the Raman spectra. A CCD detector and a $\lambda \sim 785 \mathrm{~nm}$ diode laser were used to detect the signals and do the measurement, respectively.

\subsection{Study on Adsorption-Desorption Performance and Isotherm Models}

\subsubsection{Adsorption-Desorption Study}

For the adsorption-desorption study, about $500 \mathrm{~mL}$ of $6 \mathrm{mg} \mathrm{L}^{-1}$ of $\mathrm{PO}_{4}{ }^{3-}$ was taken in a cylindrical flask to conduct batch experiments. About $1 \mathrm{mg} \mathrm{L}^{-1}$ of Z-A and iron-Z-A was introduced into the flasks separately. It was stirred with an overhead stirrer, and the $\mathrm{pH}$ was controlled at $\mathrm{pH} \leq 5$ for the adsorption experiment and at $\mathrm{pH} \leq 10$ for the desorption experiment by an auto $\mathrm{pH}$ controller (DIK, WSP100, Korea). Approximately $0.1 \mathrm{~N} \mathrm{HCl}$ and $\mathrm{NaOH}$ were used to alter the $\mathrm{pH}$ of the adsorption and desorption experiments, respectively. Sampling was done at 5, 10, 20, 30, 60, 90, and 120 min interval and the concentration was analyzed using the standard method [42]. 


\subsubsection{Adsorption Isotherm Models}

In order to evaluate the adsorption capacity, $0.1 \mathrm{~g} \mathrm{~L}^{-1}, 0.25 \mathrm{~g} \mathrm{~L}^{-1}, 0.5 \mathrm{~g} \mathrm{~L}^{-1}, 1.0 \mathrm{~g} \mathrm{~L}^{-1}, 0.2 \mathrm{~g}$ $\mathrm{L}^{-1}$, and $4.0 \mathrm{~g} \mathrm{~L}^{-1}$ of Iron-Z-A were taken separately in 6 beakers containing $500 \mathrm{~mL}$ of $6 \mathrm{mg} \mathrm{L}^{-1}$ of $\mathrm{PO}_{4}{ }^{3-}$ solution. Sampling was done at $0 \mathrm{~min}, 5 \mathrm{~min}, 10 \mathrm{~min}, 15 \mathrm{~min}, 30 \mathrm{~min}, 45 \mathrm{~min}, 60 \mathrm{~min}, 90 \mathrm{~min}$, and $120 \mathrm{~min}$ (Supplementary Figure S5). Langmuir and Freundlich's adsorption isotherm models were applied to explain the equilibrium studies. To fit the equilibrium data, these two models were employed, which helped in comprehending the mechanisms behind the adsorption-desorption of phosphate by zeolite.

\subsection{Adsorption Kinetic Study}

Predicting the adsorption rate is very crucial to plan an adsorption system. The dimensions of the reactor and residence time of adsorbate depend on the kinetics of the adsorption system. Pseudo-first-order and pseudo-second-order are the models that are frequently used to examine. The pseudo-first order kinetic model implies physisorption and the pseudo-second-order kinetic model refers to the chemisorption process. Physisorption depends on temperature and pressure, whereas a chemisorption process depends on interacting chemical bonds between the adsorbent and adsorbate. More is the surface are, more will be the possibility of active sites or bond formation, leading to an increase in the chemisorption process $[25,43-46]$.

\subsection{Adsorption-Desorption Mechanism Study}

The freshly synthesized Z-A and iron-Z-A, P adsorbed and desorbed iron-Z-A were characterized with SEM, EDS, XRD, EPR, FT-IR, Raman, and XPS to understand and decipher the undergoing mechanism behind adsorption and desorption of phosphate by iron-Z-A in an aqueous solution in an adsorption and desorption cycle.

\section{Results and Discussion}

\subsection{Characterization of the Zeolite Samples}

\subsubsection{SEM and EDS Analysis}

The SEM images of freshly prepared Z-A and iron-Z-A are shown in Figure 1a,b, respectively. In the SEM image, both samples look complete hexahedron shape and well crystallized. The crystals of Iron-Z-A was found to be rough in contrast to Z-A. The roughness on the surface of iron-Z-A acts as evidence for iron (oxide). The SEM pictures of iron-Z-A after adsorption and desorption experiments are portrayed in Figure 1c,d. It can be clearly observed that the adsorption-desorption of phosphate did not affect the hexahedron shape of the iron-Z-A. A lump of adsorbed mass can be seen on the surface of $\mathrm{PO}_{4}{ }^{3-}$ adsorbed iron-Z-A (Figure 1c). Similarly, a cleaner surface of iron-Z-A can be seen in $\mathrm{PO}_{4}{ }^{3-}$ desorbed iron-Z-A (Figure 1d), as the lump from the surface is removed. $\mathrm{PO}_{4}{ }^{3-}$ desorbed Iron-Z-A looks very much similar to freshly prepared Iron-Z-A in Figure $1 \mathrm{~b}$. It hints at the proper adsorption and desorption of $\mathrm{PO}_{4}{ }^{3-}$ by Iron-Z-A.

Based on EDS, the atomic compositions of all the four samples were analyzed and are given in Supplementary Table S1. The EDS result shows the absence and presence of iron in Z-A and Iron-Z-A, respectively. The atomic weight $\%$ values of phosphorus in phosphate adsorbed Iron-Z-A and phosphate desorbed also confirm the adsorption and desorption of $\mathrm{PO}_{4}{ }^{3-}$ by Iron-Z-A. 

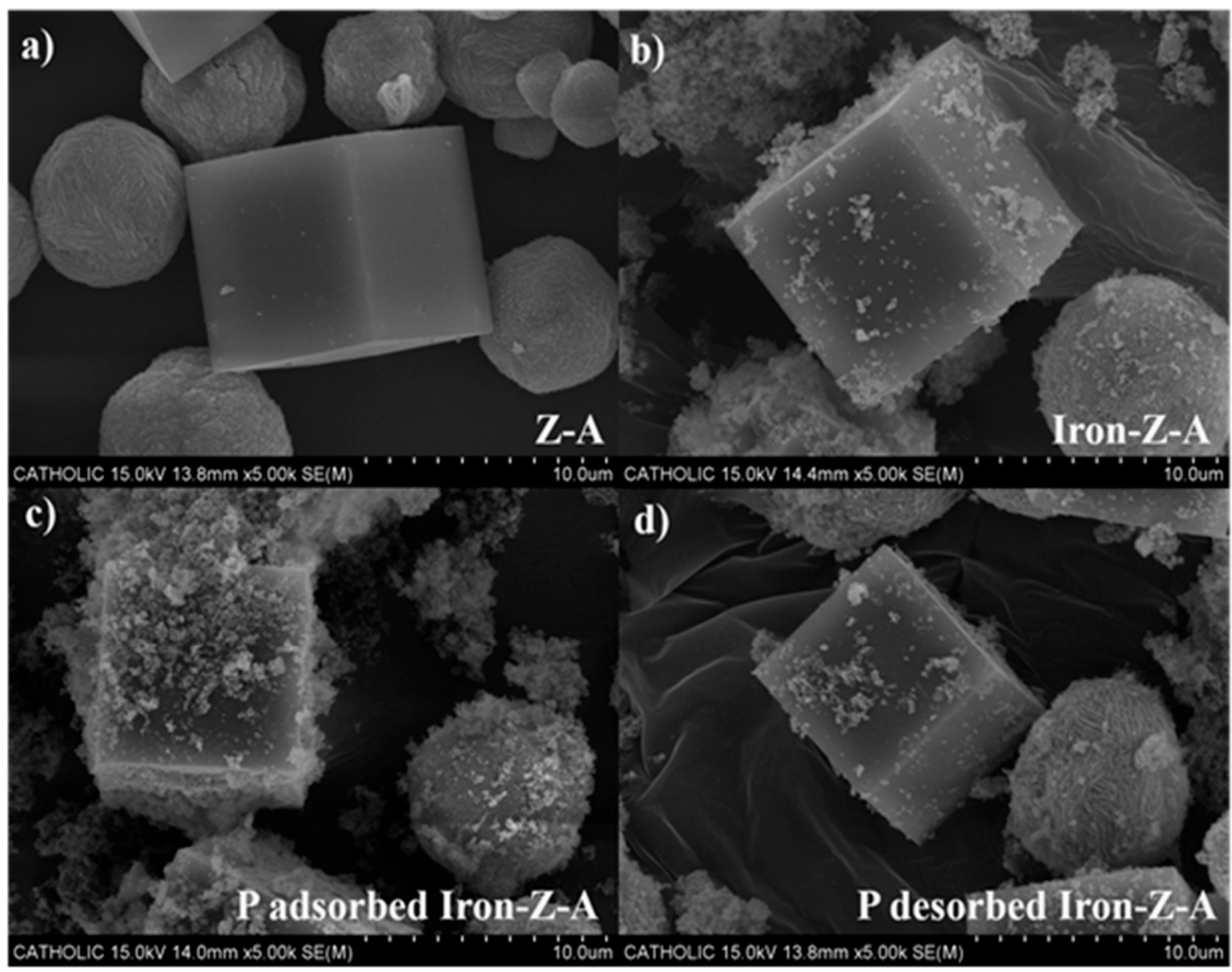

Figure 1. SEM images of (a) fresh zeolite-A (Z-A), (b) fresh iron-Z-A, (c) P-adsorbed iron-Z-A, and (d) P-desorbed iron-Z-A respectively.

\subsubsection{Electron Paramagnetic Resonance}

EPR spectra of pristine iron-Z-A, P-adsorbed iron-Z-A, and P-desorbed iron-Z-A are exhibited in Figure 2. The EPR spectrum of pristine Iron-Z-A showed a broad and high-intensity signal up to 510.794 a.u. possessing ' $\mathrm{g}$ ' value $=2.014$. In the case of P-adsorbed Iron-Z-A, the broad peak intensity spiked up to 572.753 a.u. and showed ' $g$ ' value $=2.015$. Similarly, in P-desorbed Iron-Z-A, the peak intensity went up to 723.746 a.u. with ' $\mathrm{g}$ ' value $=2.010$. The ' $\mathrm{g}$ ' value is $\sim 2.0 \mathrm{in}$ all the zeolite species exhibited that the iron in the zeolite was incorporated in the framework in the form of $\mathrm{Fe}_{\mathrm{x}} \mathrm{O}_{\mathrm{y}}$ clusters or $\mathrm{Fe}_{2} \mathrm{O}_{3}$ nanoparticles. The successive increase in the peak intensity of virgin iron-Z-A, P-adsorbed iron-Z-A, and P-desorbed iron-Z-A suggested the successive exposure of iron species in the zeolite framework due to the adsorption and desorption process. Although there is a change in peak intensity but no significant change in the ' $\mathrm{g}$ ' value, which proved the firm incorporation of Fe in the zeolite framework. The wide peak intensities in the signals showed the presence of $\mathrm{Fe}^{3+}$ ions. A very weak intensity shoulder peak in P-adsorbed Iron-Z-A and P-desorbed iron-Z-A can be observed with ' $\mathrm{g}$ ' value $=4.182$ and 4.173 , respectively. These new peaks in P-adsorbed and P-desorbed iron-Z-A give evidence for the appearance of new active sites. 


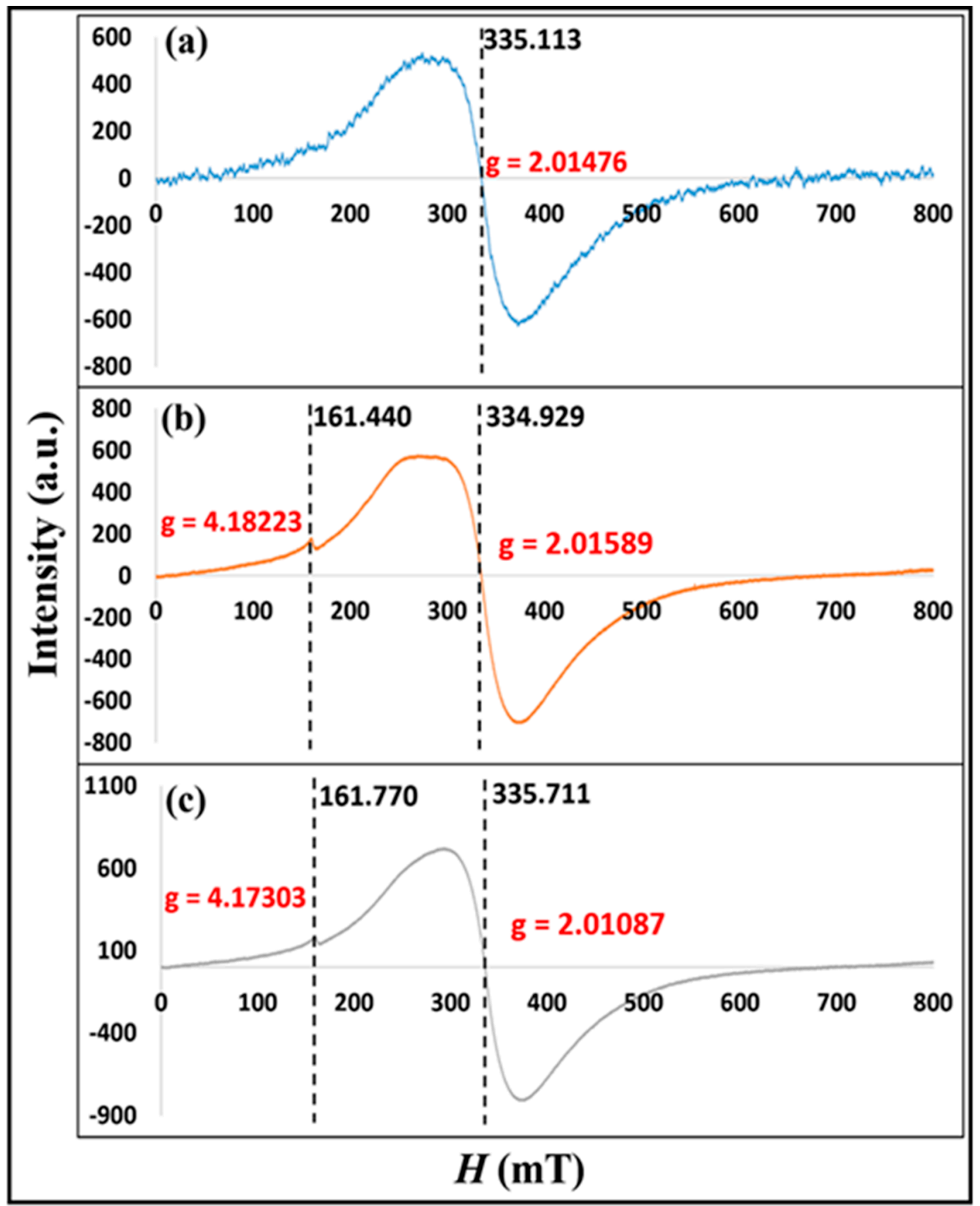

Figure 2. EPR spectra of (a) pristine Iron-Z-A, (b) P-adsorbed Iron-Z-A, and (c) P-desorbed Iron-Z-A.

\subsubsection{FT-IR Analysis Results}

The results of FT-IR spectroscopy of fresh iron-Z-A, phosphate adsorbed iron-Z-A, and phosphate desorbed iron-Z-A can be seen in Figure 3. In the $4000-400 \mathrm{~cm}^{-1}$ region, the IR spectra of the zeolite frameworks can be seen. The IR vibration in the zeolite spectra of fresh Z-A backbone consists of -OH stretching and bending vibration at 3467.78 and 1653.85 , respectively. These are the bands which are formed due to the $\mathrm{OH}$ groups. These $\mathrm{OH}$ groups are as; (i) $\mathrm{OH}$ groups which balance the negative charge by attaching to $\mathrm{Fe}^{3+}$, (ii) $\mathrm{OH}$ groups taking place at defects, and (iii) $\mathrm{Si}-\mathrm{O}-\mathrm{H}$ groups at lattice ends [47] $\mathrm{Si}-\mathrm{O}(\mathrm{Si})$ and $\mathrm{Si}-\mathrm{O}(\mathrm{Al})$ bridge bond's asymmetric stretching vibration can be seen at 993.27 due to. $\mathrm{Si}-\mathrm{O}-\mathrm{Si}$ and $\mathrm{Si}-\mathrm{O}-\mathrm{Al}$ bridge bond's symmetric bridge vibrations at 734.83 and 668.29 respectively, bending vibrations of $\mathrm{O}-\mathrm{Si}-\mathrm{O}$ bond in antiphase at 441.67 , bending vibration of $\mathrm{O}-\mathrm{Si}-\mathrm{O}$ and $\mathrm{Si}-\mathrm{O}-\mathrm{Si}$ 
bridge bond's symmetric stretching vibrations (complex band) at 569.92 can be observed. The internal vibration at $993 \mathrm{~cm}^{-1}$ indicates O-T-O asymmetrical stretching modes. The shifts of these bands IR spectra in the backbone of Iron-Z-A, phosphate adsorbed iron-Z-A, and phosphate desorbed iron-Z-A are shown in Table 1. According to Pham et al. (2016) [48], the peak at $480-560 \mathrm{~cm}^{-1}$ is a characteristic of iron-nano zeolite [48]. The change in intensity of -OH bonds of P-adsorbed Iron-Z-A and P desorbed Iron-Z-A from fresh Iron-Z-A shows the participation of the hydroxyl group in phosphate adsorption. The revival in -OH bond intensity of $\mathrm{P}$ desorbed Iron-Z-A affirms its participation in the desorption of phosphate. Hence, the involvement of $-\mathrm{OH}$ bond in both adsorption and desorption of phosphate hints the existence of the ligand exchange mechanism. Further fall in intensity after adsorption of phosphate and revival of peak intensity after desorption of phosphate also suggests adsorption and desorption of phosphate by Al.

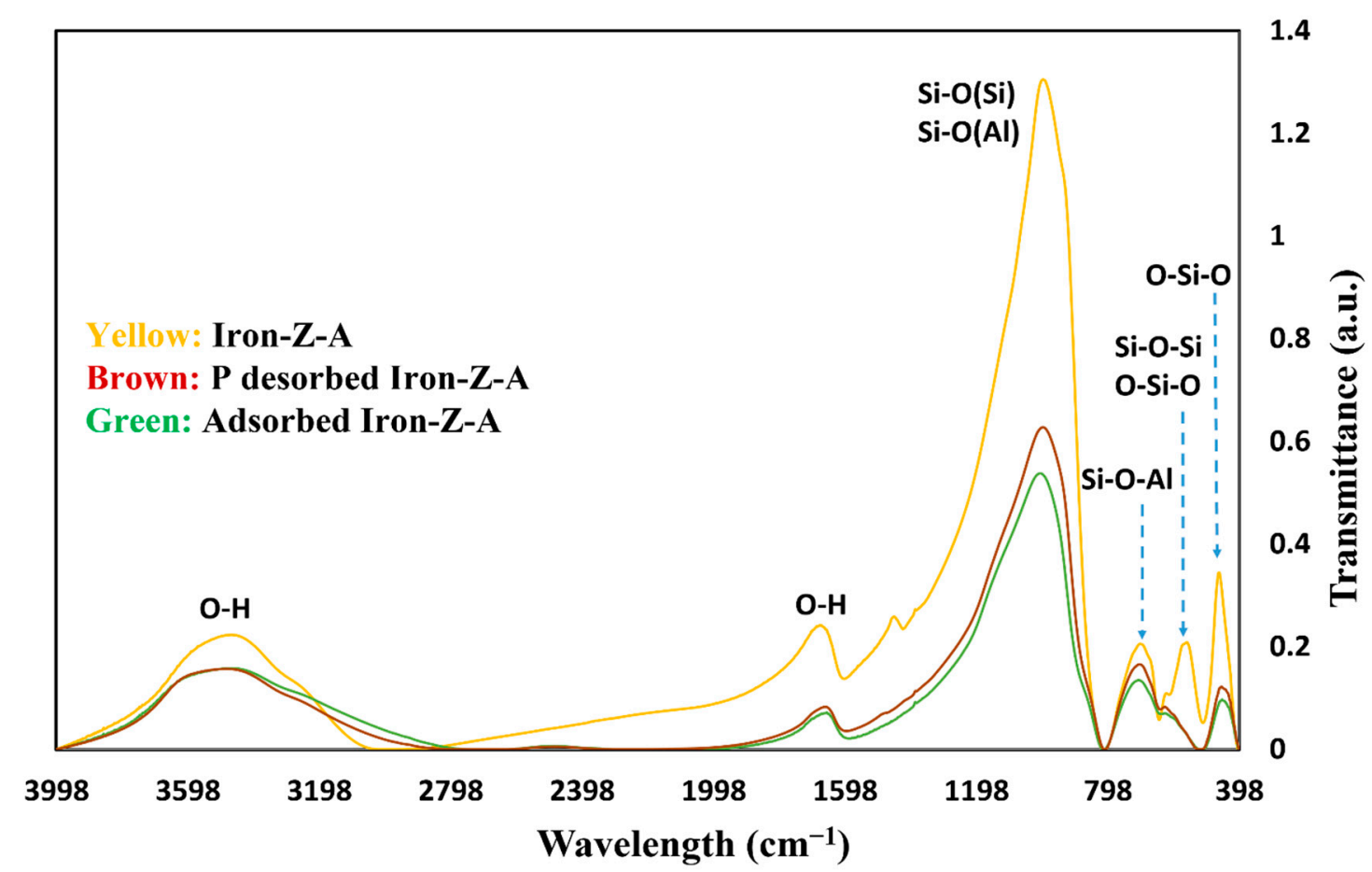

Figure 3. The FT-IR spectrum of different bonds on the fresh Iron-Z-A, P-adsorbed Iron-Z-A, and P-desorbed Iron-Z-A backbone.

Table 1. FT-IR bond stretching and vibrations of different band peak shifts in the IR spectra of the zeolite backbone.

\begin{tabular}{ccccc}
\hline \multirow{2}{*}{$\begin{array}{c}\text { The Vibration of the } \\
\text { Following Bonds }\end{array}$} & \multicolumn{3}{c}{ Band Peak Shift in IR Spectra of the Zeolite Backbone } \\
\cline { 2 - 5 } & Fresh Z-A & Fresh Iron-Z-A & P-Adsorbed Iron-Z-A & P-Desorbed Iron-Z-A \\
\hline$-\mathrm{OH}$ strectching & 3467.78 & 3466.82 & 3462.96 & 3481.28 \\
$-\mathrm{OH}$ bending & 1653.85 & 1652.88 & 1652.88 & 1657.71 \\
$-v_{\text {as }} \mathrm{Si}-\mathrm{O}(\mathrm{Si}) \& v_{\mathrm{as}} \mathrm{Si}-\mathrm{O}(\mathrm{Al})$ & 993.27 & 995.20 & 1001.95 & 996.16 \\
$-v_{\mathrm{s}} \mathrm{Si}-\mathrm{O}-\mathrm{Si}$ & 734.83 & 700.11 & 705.90 & 701.07 \\
$-v_{\mathrm{s}} \mathrm{Si}-\mathrm{O}-\mathrm{Al}$ & 668.29 & 556.42 & 705.90 & 701.07 \\
$-v_{\mathrm{s}} \mathrm{Si}-\mathrm{O}-\mathrm{Si} \&-\delta$ O-Si-O & 569.92 & 556.42 & & 452.27 \\
$-\delta$ O-Si-O & 441.67 & 459.02 & 450.34 & 4 \\
\hline
\end{tabular}

\subsubsection{XRD Analysis}

The X-ray crystallography patterns of fresh Z-A, fresh iron-Z-A, P-adsorbed Iron-Z-A, and P desorbed Iron-Z-A are shown in Figure 4. The XRD characteristic peak of Z-A appeared at 7.2, $10.3^{\circ}$, $12.6^{\circ}, 16.2^{\circ}, 21.8^{\circ}, 24^{\circ}, 26.2^{\circ}, 27.2^{\circ}, 30^{\circ}, 30.9^{\circ}, 31.1^{\circ}, 32.6^{\circ}, 33.4^{\circ}$, and $34.3^{\circ}$ [49] in both fresh Z-A 
and Iron-Z-A. It suggested that in both the samples, the surface crystallinity of Z-A was adequately formed. The crystallinity of Z-A was found to be 84.529 whereas, in the case of Iron-Z-A, it was 78.343. It can be observed that there is a slight decline in the XRD peak intensity of iron-Z-A. The fall in the crystallographic pattern hints at the uniformity of iron in the zeolite [39]. However, a distinct XRD peak of Z-A spiked at $27.9^{\circ}$, which is considered to be a sodalite peak. This peak also appeared in Iron-Z-A because sodalite was partially synthesized during the synthesis of Z-A. The XRD patterns of P-adsorbed and P desorbed Iron-Z-A showed no peaks. The surface of fresh Iron-Z-A transformed from the phase of crystallinity to amorphic after the adsorption of phosphate. The more is the surface amorphicity, the more will it have active sites [47] or adsorption capacity [50], which is also supported by the EPR results.

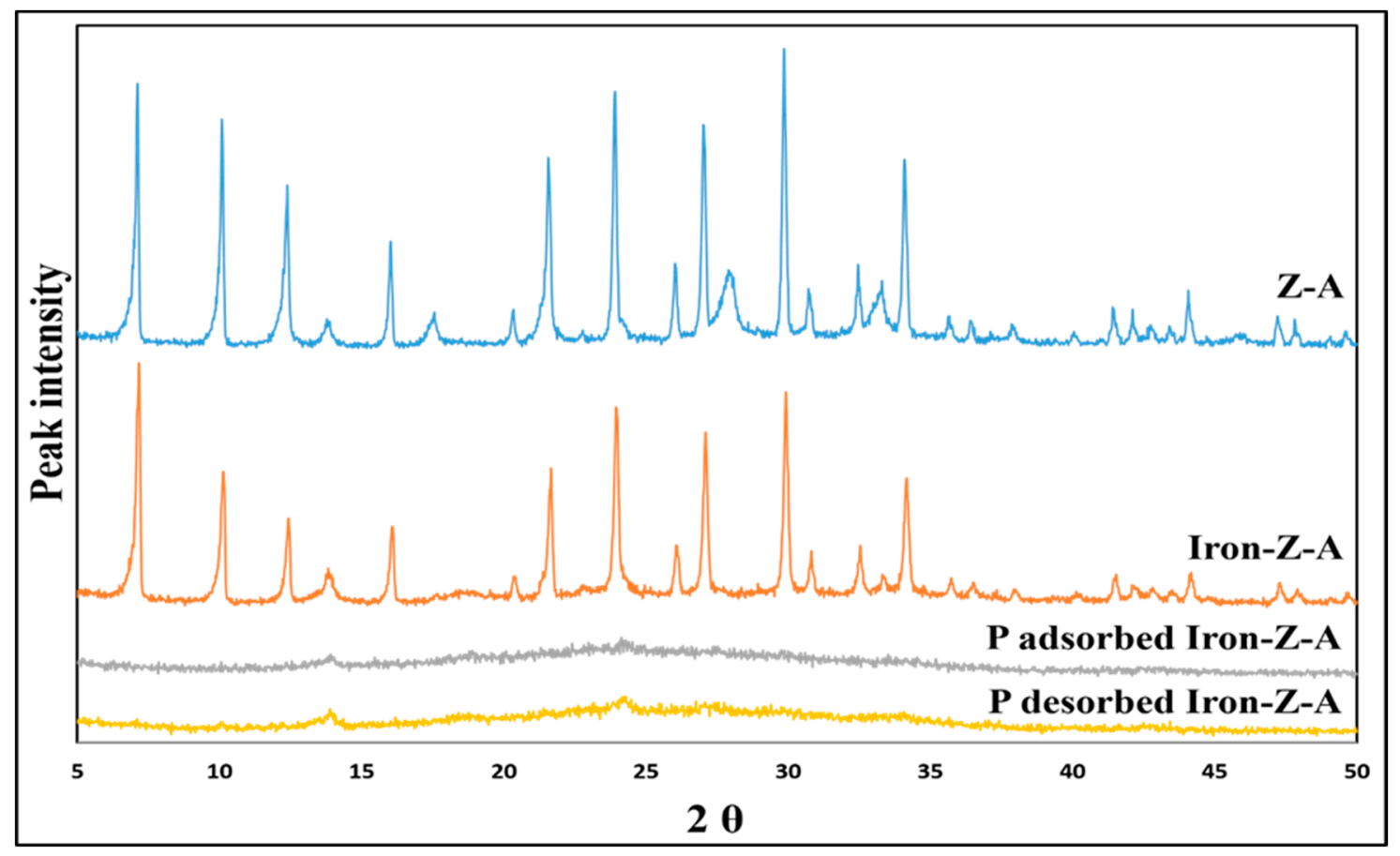

Figure 4. Illustration of XRD patterns of fresh Z-A, fresh Iron-Z-A, P-adsorbed Iron-Z-A, and P-desorbed Iron-Z-A.

\subsubsection{XPS Analysis}

The XPS data of fresh Z-A, fresh Iron-Z-A, P-adsorbed Iron-Z-A, and P desorbed Iron-Z-A shows the peaks of Fe $2 p$ appeared in the region between 706 730 eV binding energy. As shown in Figure 5, for fresh iron-Z-A, the centers of electron binding energy of $\mathrm{Fe} 2 \mathrm{p}^{1 / 2}$ and $\mathrm{Fe} 2 \mathrm{p}^{3 / 2}$ at 724.48 and 711.08 respectively are quite closer to the standard data of $\mathrm{Fe}_{2} \mathrm{O}_{3}$. At the binding energy $722.18 \mathrm{eV}\left(\mathrm{Fe}-2 \mathrm{p}^{3 / 2}\right)$, the shakeup satellite peak is a fingerprint of the electronic structure of $\mathrm{Fe}^{3+}$ and tells that $\mathrm{Fe}^{2+}$ is absent [35]. No peak was observed for Z-A as it did not contain iron in the zeolite frame. The peak of Fe-2p appeared in the region 706-718 eV of binding energy. The Fe $2 p$ peaks of P-adsorbed Iron-Z-A appeared at a higher energy side $(711.48 \mathrm{eV})$ than fresh Iron-Z-A, whereas it shifted to the lower energy side $(711.28 \mathrm{eV})$ for P desorbed Iron-Z-A. The peak shift trend after adsorption and desorption suggests a reversible pattern. Phosphate adsorbed and desorbed Iron-Z-A exhibits a characteristic peak at about $711.1 \mathrm{eV}$, indicating the binding energy of $\mathrm{Fe}_{2} \mathrm{O}_{3}\left(\mathrm{Fe}^{3+}\right)$ [51]. The similar peaks of $\mathrm{Fe}$ in adsorbed and desorbed Iron-Z-A also signifies that the bond strength between Fe and phosphate is high.

The Si 2p peak of Iron-Z-A with iron in the IR spectrum slightly shifted as compared to Z-A's Si $2 p$ peak. The peak of $\mathrm{Si} 2 \mathrm{p}$ shifted when $\mathrm{Si}-\mathrm{O}-\mathrm{Fe}$ bonds were formed because the bond-lengths in $\mathrm{Si}-\mathrm{O}-\mathrm{Fe}$ are bigger than the bond-lengths in $\mathrm{Si}-\mathrm{O}-\mathrm{Al}$ [51]. Therefore, the shifting in the peak indicated that iron was substituted into the zeolite structure. It was supported by the findings of SEM-EDS, XRD, 
and FTIR. The Si 2p peak appeared in the region between 99 and $105 \mathrm{eV}$ of binding energy, as shown in Figure 5 . The Si $2 p$ peak of iron-Z-A also slightly shifted in both phosphate adsorbed iron-Z-A as well as phosphate desorbed iron-Z-A. Si was not directly combined with phosphate; however, the crowding of phosphate atoms in its vicinity may have shifted the Si peak in the case of both; phosphate adsorbed iron-Z-A and phosphate desorbed iron-Z-A.

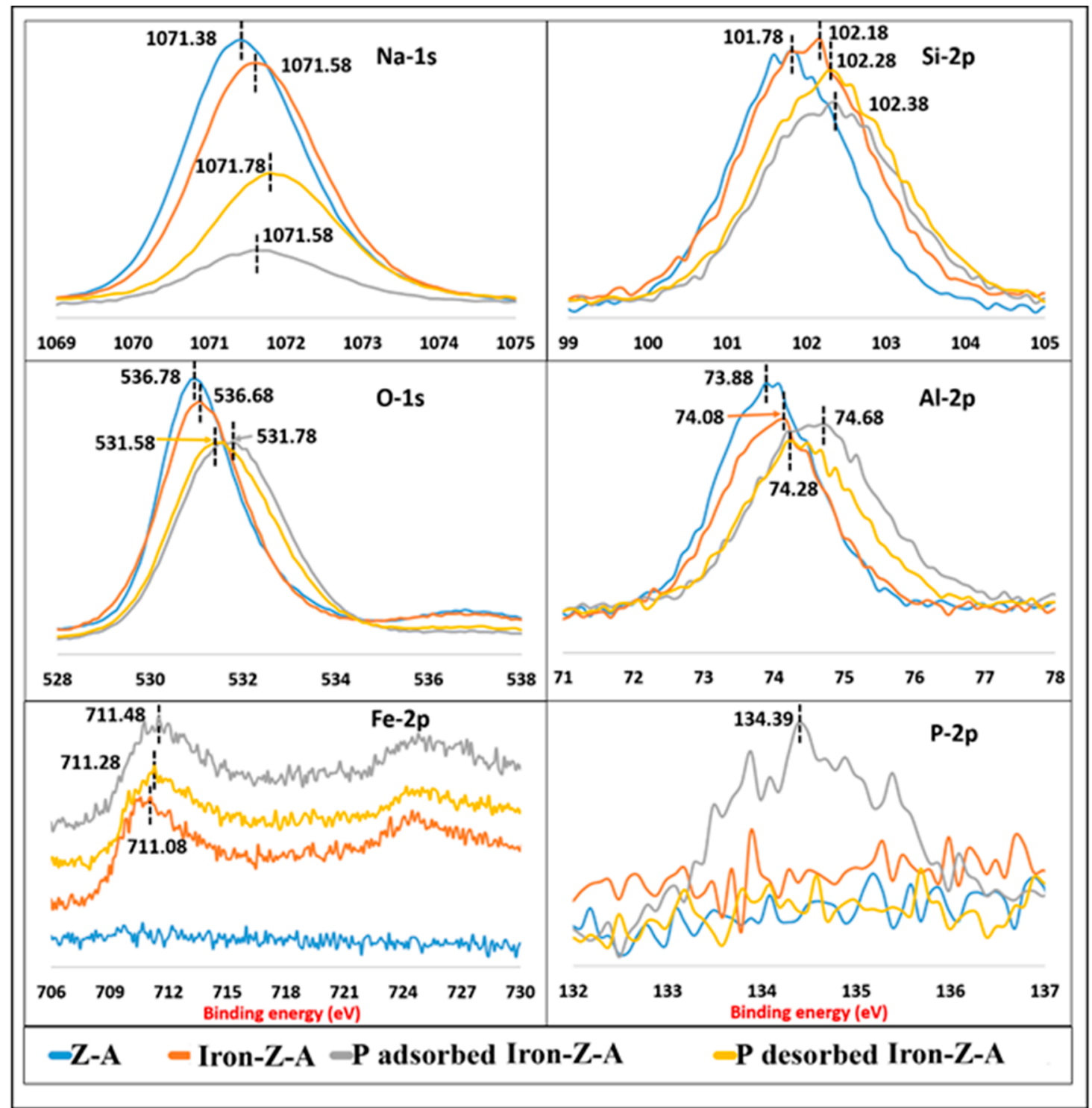

Figure 5. Illustration of XPS spectra of $\mathrm{Na} 1 \mathrm{~s}, \mathrm{Si} 2 \mathrm{p}, \mathrm{O} 1 \mathrm{~s}, \mathrm{Al} 2 \mathrm{p}, \mathrm{Fe} 2 \mathrm{p}$, and P 2p in the framework of fresh Z-A, fresh iron-zeolite-A (Iron-Z-A), P-adsorbed Iron-Z-A, and P-desorbed Iron-Z-A.

The change in the intensity of the $\mathrm{Al} 2 \mathrm{p}$ peak of Iron-Z-A than $\mathrm{Al} 2 \mathrm{p}$ of Z-A suggested the weaker interaction of aluminum in the zeolite backbone. The XPS spectra in the Al $2 p$ region of Iron-Z-A, as shown in Figure 5, appeared in the region $71-78 \mathrm{eV}$ of binding energy. It can be observed that the Al $2 \mathrm{p}$ peak of phosphate adsorbed Iron-Z-A slightly shifted to a higher energy side as compared to fresh Iron-Z-A. This shifting of the Al 2p peak indicated that $\mathrm{Al}$ interacted with phosphate. However, Al peak of phosphate desorbed Iron-Z-A moved towards lower energy in comparison to $\mathrm{Al}$ of fresh Iron-Z-A, and binding energy was similar to that of fresh Iron-Z-A. Hence, it confirmed that $\mathrm{Al}$ in the Iron-Z-A is also contributing to the adsorption. 
The P $2 p$ peak appeared in the region 132-137 eV of binding energy, as shown in Figure 5. The phosphate adsorbed Iron-Z-A showed a peak at $134.39 \mathrm{eV}$ for P 2p, which clarified the adsorption of phosphate on the zeolite's surface. Phosphate desorbed iron-Z-A did not show any peak for P 2p, which confirms that the phosphate is well desorbed.

The fall in peak intensity of $\mathrm{O}$ 1s spectra of fresh Iron-Z-A than fresh Z-A confirmed the accommodation of $\mathrm{Fe}$ in its vicinity. The change in peak intensity and peak shift of $\mathrm{O} 1 \mathrm{~s}$ of in the P-adsorbed Iron-Z-A and P desorbed Iron-Z-A than fresh iron-Z-A suggested the interaction of oxygen in the adsorption-desorption process. The O 1s XPS spectra of P-adsorbed iron-Z-A shifted to the higher energy side, but in the case of $\mathrm{P}$ desorbed, iron-Z-A shifted back towards the lower energy side, and the peak intensity remained the same.

In the case of the XPS spectra of $\mathrm{Na} 1 \mathrm{~s}$, there is a big decline in its peak intensity than peak shift. The decrease in intensity of $\mathrm{Na} 1 \mathrm{~s}$ of iron-Z-A than Z-A is probably due to the dispersion of Fe into the $\mathrm{Z}-\mathrm{A}$ framework and replacement of $\mathrm{Na}^{+}$with $\mathrm{Fe}^{3+}$ ions in the framework. In the acidic $\mathrm{pH}$ during the adsorption phase, the $\mathrm{Na}^{+}$ion might have been replaced with $\mathrm{H}^{+}$ion. So, there is a sharp decline in the peak intensity of P-adsorbed Iron-Z-A as compared to fresh Iron-Z-A. The revival in peak intensity of $\mathrm{Na}$ 1s of $\mathrm{P}$ desorbed Iron-Z-A suggests the replacement of $\mathrm{Na}^{+}$ion onto the Iron-Z-A surface.

The results of XPS of all the samples suggest that $\mathrm{Fe}$ and $\mathrm{Al}$ exhibited a pivotal part in the adsorption of phosphate, whereas in the case of desorption, $\mathrm{Al}$ only actively desorbed phosphate. As already mentioned, Fe cannot desorb $\mathrm{PO}_{4}{ }^{3-}$ easily due to the strong attraction force existing between them. Therefore, Al plays a key role in the regeneration of Iron-Z-A for further use.

\subsubsection{Raman Analysis}

The Raman spectra of fresh, P-adsorbed and P-desorbed iron-Z-A have been shown in Figure 6. The Raman analysis of phosphate adsorbed Iron-Z-A showed changes in the peak position and intensity as compared with the pristine Iron-Z-A. The peak at $200 \mathrm{~cm}^{-1}$ region, $\mathrm{T}-\mathrm{O}-\mathrm{T}$ angle at $490 \mathrm{~cm}^{-1}$, and asymmetric stretching at $1000-1100 \mathrm{~cm}^{-1}$ region in all the three samples is due to characteristic stretching and bending of Z-A. The bands between 650 and $750 \mathrm{~cm}^{-1}$ are due to the presence of a double four rings (D4R) of Z-A [52]. The bands at $800-900 \mathrm{~cm}^{-1}, 500 \mathrm{~cm}^{-1}$ regions, and $1250-1350 \mathrm{~cm}^{-1}$ region show $\mathrm{P}-\mathrm{O}-\mathrm{P}$ bridges, bending vibrations of $\mathrm{P}-\mathrm{O}$ bonds, and $\mathrm{P}=\mathrm{O}$ stretching respectively [53], where the intensity of band increases at $800-900 \mathrm{~cm}^{-1}$ and decreases at $1300 \mathrm{~cm}^{-1}$ with the increase in phosphate content. The peaks observed at $1300 \mathrm{~cm}^{-1}$ and $1600 \mathrm{~cm}^{-1}$ in all the three samples claims the formation of $\mathrm{Fe}_{2} \mathrm{O}_{3}$ in the zeolite structure [54,55]. In the region of 1250 and $1350 \mathrm{~cm}^{-1}$, it showed symmetric stretching of $\mathrm{P}-\mathrm{O}$ [53]. The change in peak's intensity in the region of $1300 \mathrm{~cm}^{-1}$ of P-adsorbed and P-desorbed Z-A is due to the formation of $\mathrm{Fe}-\mathrm{O}-\mathrm{P}$ bond. In P-adsorbed Z-A, there is a rise in the intensity of the band centered at $1104 \mathrm{~cm}^{-1}$ was due to the peaks of adsorbed $\mathrm{PO}_{4}{ }^{3-}$ appeared in the range of $800-900 \mathrm{~cm}^{-1}$ and thus broadened the band, whereas we can see the absence of any peak in the same region $850-900 \mathrm{~cm}^{-1}$, due to desorption of $\mathrm{PO}_{4}{ }^{3-}$ from iron-Z-A. The spectrum of phosphate desorbed iron-Z-A showed a noteworthy shift (from $1004 \mathrm{~cm}^{-1}$ to $1050 \mathrm{~cm}^{-1}$ ) along with increased intensity for the interlayer anion band. The RRUFF database proves that the peaks near $400 \mathrm{~cm}^{-1}$ and between $1200 \mathrm{~cm}^{-1}$ and $1400 \mathrm{~cm}^{-1}$ in the fresh, P-adsorbed, and P-desorbed Iron-Z-A are due to $\mathrm{Fe}_{2} \mathrm{O}_{3}$ in the zeolite framework [56]. 


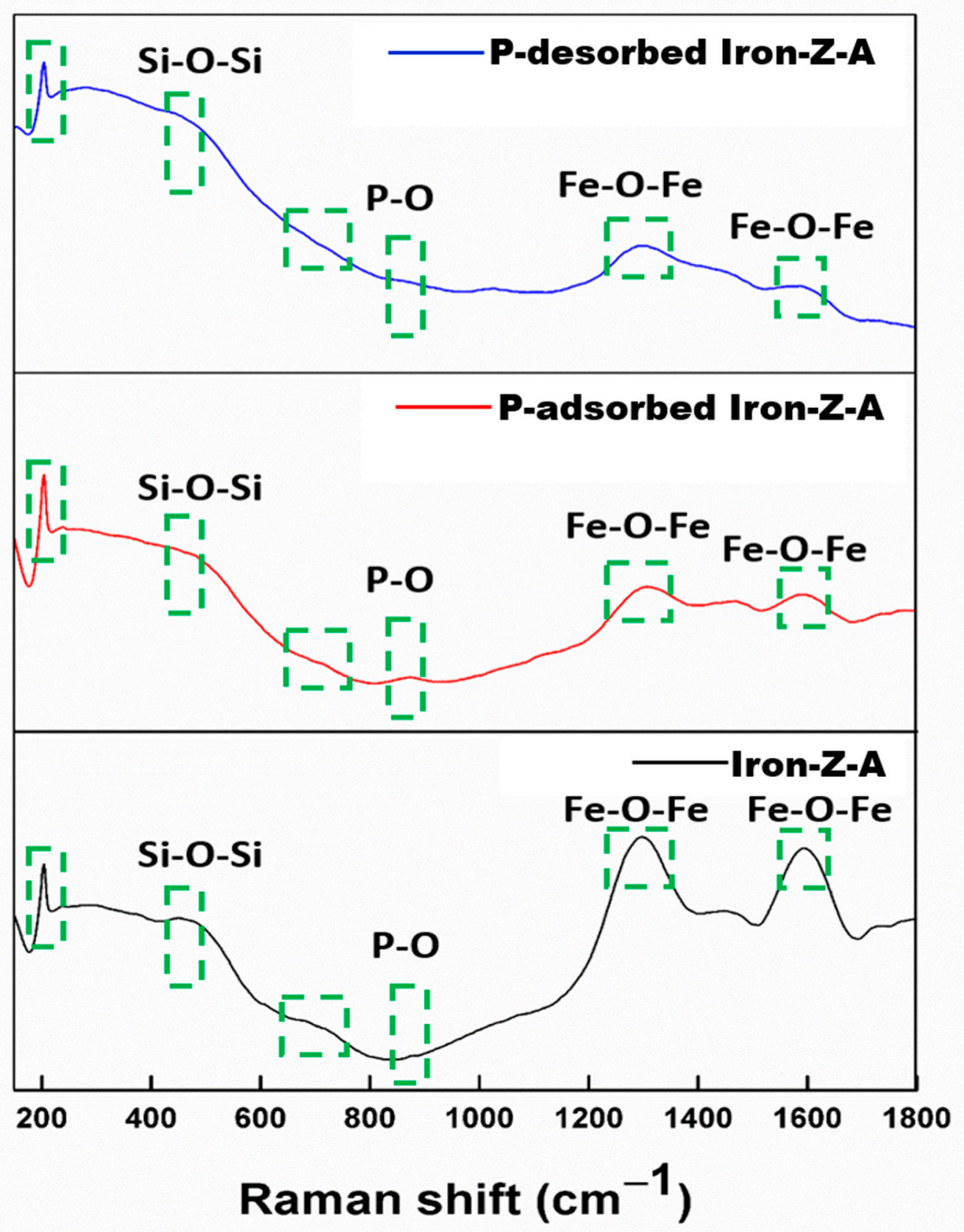

Figure 6. Shifts in peaks of FT-Raman of Iron-Z-A, P-adsorbed Iron-Z-A, and P-desorbed Iron-Z-A.

\subsection{Study on Adsorption-Desorption and Isotherm Models}

\subsubsection{Adsorption-Desorption Study}

Adsorption and desorption experiments for Z-A and Iron-Z-A were performed at $\mathrm{pH} \leq 5$ and $\mathrm{pH} \leq 10$, respectively, after optimization of $\mathrm{pH}$. Adsorption desorption data are given in Supplementary Figure S3 \& S4. Iron-Z-A showed much better adsorption capacity than Z-A.

\subsubsection{Adsorption Isotherm Models}

To fit the equilibrium data, Langmuir and Freundlich's models were employed. It assists in deciphering the mechanism behind phosphate adsorption by zeolite. The values of constants and 
coefficients of correlation applied to both the adsorption isotherm models are also presented in Table 2. Langmuir's isotherm demonstrated a better fit than that of Freundlich's isotherm with higher correlation coefficient values. In addition, the value of $Q_{m}$ was also significantly high in the case of Langmuir, as compared to Freundlich, whose $Q_{m}$ values are found to be negative. This result indicated that the phosphate is uniformly adsorbed on the adsorbent's surface, and the adsorbed adsorbate's amount depends on the dosage of adsorbent or the exposed adsorbent's surface, irrespective of phosphate concentration.

Table 2. Values of constants of Langmuir and Freundlich's isotherm models for phosphate adsorption by iron-Z-A.

\begin{tabular}{cccccc}
\hline \multicolumn{3}{c}{ Langmuir } & \multicolumn{4}{c}{ Freundlich } \\
\hline$K_{L}(\mathrm{~L} / \mathrm{mg})$ & $\mathbf{Q}_{\mathrm{m}}$ & $\boldsymbol{R}^{2}$ & $\boldsymbol{K}_{\boldsymbol{F}}(\mathrm{mg} / \mathrm{g}) /(\mathrm{mg} / \mathrm{L})^{1 / 2}$ & $n$ & $\boldsymbol{R}^{2}$ \\
\hline-2.51 & 2.16 & 0.92 & 134.62 & -0.29 & 0.67 \\
\hline
\end{tabular}

By considering the amount of $\mathrm{PO}_{4}{ }^{3-}$ being adsorbed by Z-A (only $\mathrm{Al}$ ) and iron-Z-A ( $\mathrm{Fe}+\mathrm{Al}$ ), we calculated the amount $\mathrm{PO}_{4}{ }^{3-}$ being adsorbed by $\mathrm{Fe}$ and $\mathrm{Al}$ individually. From Table 3, it is clear that the adsorption capacity $\mathrm{PO}_{4}{ }^{3-}$ increased seven times by adding $\mathrm{Fe}$ to the $\mathrm{Z}$-A framework.

Table 3. Illustration of the amount of adsorbed phosphate on different metal compounds of adsorbent in $\mathrm{mg} / \mathrm{g}$.

\begin{tabular}{cc}
\hline Metal Ion & Adsorbed Phosphate/Adsorbent (mg/g) \\
\hline Fe & $382.296 \mathrm{mg} \mathrm{PO}_{4}{ }^{3-} / \mathrm{g} \mathrm{Fe}$ \\
$\mathrm{Al}$ & $56.296 \mathrm{mg} \mathrm{PO}_{4}{ }^{3-} / \mathrm{g} \mathrm{Al}$ \\
\hline
\end{tabular}

It can easily be calculated from the above data that the amount of $\mathrm{P}$ captured by Fe is greatly high or ten folds higher than that of Al. These results are considered consistent with the results perceived in the adsorption kinetics study.

\subsection{Adsorption Kinetic Study}

The different factors of kinetic models for phosphate adsorption on iron-Z-A are displayed in Table 4. To investigate the mechanism behind phosphate adsorption on iron-Z-A, we performed kinetic analysis using the first-order and second-order of pseudo-kinetic models. The pseudo-second-order kinetic model showed a more desirable linear relationship as shown in Figure 7. The order of the reaction was determined by log plotting. The inverse plot obtained for second-order reaction is being shown in the Supplementary Figure S6.

The experimental data of phosphate onto iron-Z-A fits better in the pseudo-second-order kinetic model, which is illustrated in Table 4. It is also indicated that the chemisorption process between the adsorbent and phosphate can be a rate-limiting step by sharing or exchange of electrons $[25,45,46]$. Besides, it meant that the adsorbate's amount depends on the adsorbent's surface area regardless of the concentration [35].

Table 4. Illustration of iron-Z-A's kinetic parameters for adsorption of phosphate.

\begin{tabular}{cccc}
\hline Kinetic Models & $\boldsymbol{R}^{2}$ & $\boldsymbol{Q} \boldsymbol{e}$ & $\boldsymbol{k}_{\mathbf{1}} \& \boldsymbol{k}_{2}$ \\
\hline Pseudo-first-order model & 0.90 & -42.73 & $0.023(1 / \mathrm{min})$ \\
Pseudo-second-order model & 0.99 & 2.03 & $0.23(\mathrm{~g} / \mathrm{mg} \mathrm{min})$ \\
\hline
\end{tabular}




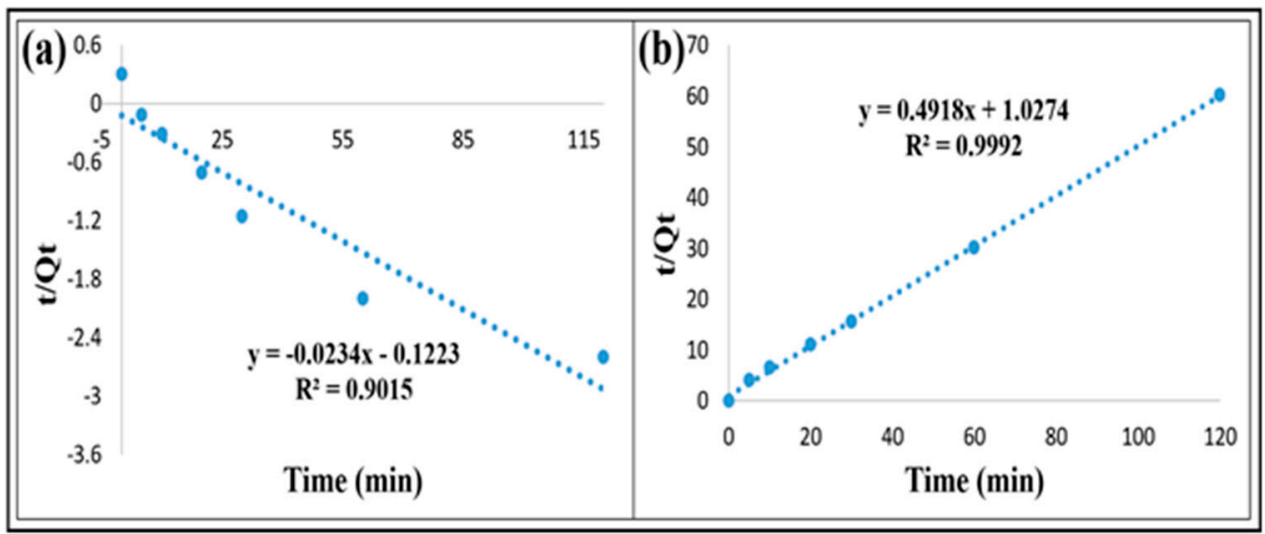

Figure 7. Pseudo-first-order and pseudo-second-order kinetics for adsorption of phosphate.

\subsection{Proposed Mechanism for Adsorption and Desorption of Phosphate by Iron-Z-A}

The XPS spectra of P 2p, SEM image and EDS data of P-adsorbed Iron-Z-A and P-desorbed Z-A confirmed the complete adsorption and desorption of $\mathrm{PO}_{4}{ }^{3-}$ from the surface of Iron-Z-A. The following explanation claims the domination of the ligand exchange mechanism in the adsorption-desorption process: (1) The P 2p XPS spectra of P-adsorbed iron-Z-A demonstrated a characteristic peak at $134.38 \mathrm{eV}$, whereas fresh iron-Z-A and P-desorbed iron-Z-A's XPS spectra did not show any characteristic P 2p peak. (2) The peak of Fe $2 \mathrm{p}$ of fresh iron-Z-A moved from $711.08 \mathrm{eV}$ to a higher energy side $(711.48 \mathrm{eV})$ after adsorption of phosphate, and the peak shifted back to the lower energy side $(711.28 \mathrm{eV})$ after desorption of phosphate. So, the XPS spectra of Fe 2p exhibited a reversible pattern. (3) The intensity of FT-IR spectra of the fresh Iron-Z-A backbone corresponding to -OH bending and stretching at 1652.89 fell from 0.23 to 0.07 for P-adsorbed Iron-Z-A and raised to 0.08 for P-desorbed Iron-Z-A. So, the peak intensity pattern of $-\mathrm{OH}$ bond showed a reversible behavior for P-adsorbed Iron-Z-A and $\mathrm{P}$-desorbed Iron-Z-A. The above points confirmed the involvement of the ligand exchange mechanism for phosphate adsorption as well as desorption by iron-Z-A. The above discussion has shown a reasonable correlation for the adsorption of phosphate to the iron-Z-A as a result of the presence of active iron sites on Z-A's surface. Although it is evident that Z-A (without iron substitution), can remove anions (including $\mathrm{PO}_{4}{ }^{3-}$ ) from water in our study, Iron-Z-A presented a much faster removal capacity than Z-A (Supplementary Figure S2). It indicates that not only positive charge bearing species $\mathrm{Na}^{+}$is active for adsorption of phosphate but also a modest amount of removal may be attributed by the interactions (hydrogen bond) between the framework of oxygen and derivative of phosphate [57]. It was confirmed by XPS results, as there was no peak detected corresponding to sodium phosphate in contrast to the peak for iron phosphate (Figure 5). In Iron-Z-A, the Fe was incorporated in the zeolite backbone in the place of aluminum and chelation on the -O-Al-O- site by replacing $\mathrm{Na}^{+}$, which increased the positive charge density centers. When Fe was substituted with $\mathrm{Al}$, it created a hole on the surface (increasing the positive charge density), which ultimately favors anion adsorption. In the reaction mixture for removal of phosphate, the positive charge of Iron-Z-A was balanced by $\mathrm{OH}^{-}$ions; when phosphate was added, it was attracted to the positive centers following the ligand-exchanged principle. As, at $\mathrm{pH} 5$, phosphate exists as $\mathrm{H}_{2} \mathrm{PO}_{4}{ }^{-}$during the adsorption phase (as a derivative of phosphate) and as $\mathrm{HPO}_{4}{ }^{2-}$ at $\mathrm{pH} 10$ during desorption, where both acts as a ligand. In aqueous phase at $\mathrm{pH} 5$, the $\mathrm{OH}^{-}$ion on the $\mathrm{Fe}$ atom of Iron-Z-A backbone gets replaced with the ligand $\mathrm{H}_{2} \mathrm{PO}_{4}{ }^{-}$(Figure 8) through ligand exchange mechanism to form "Iron Zeolite (oxy) hydroxide bound phosphate." As zeolites are more selective to $\mathrm{H}^{+}$ion, it exchanged its $\mathrm{Na}^{+}$ion crowding from its surface with $\mathrm{H}^{+}$ion in the phosphoric acid medium due to reaction with an acid $(\mathrm{HCl})$. The adsorption of $\mathrm{PO}_{4}{ }^{3-}$ on Iron-Z-A can be confirmed through the lump of deposition visible in the SEM images, spiking of $\mathrm{P} 2 \mathrm{p}$ peak in the XPS spectra, and EDS data of Iron-Z-A. In alkaline $\mathrm{pH}$, the $\mathrm{OH}^{-}$ion acts as a ligand and replaces the derivative of phosphate $\left(\mathrm{H}_{2} \mathrm{PO}_{4}{ }^{-}\right)$from Fe. In the desorption phase, the $\mathrm{H}^{+}$ion 
in the zeolite gets exchanged with $\mathrm{Na}^{+}$ion due to the addition of adequate $\mathrm{NaOH}$ to maintain alkalinity. Similarly, to confirm the desorption of $\mathrm{PO}_{4}{ }^{3-}$ from the surface of Iron-Z-A, we can refer to the SEM images, no appearance of a peak in P 2p XPS spectra, and EDS data of P desorbed Iron-Z-A sample. A detailed graphical representation of the proposed mechanism is reproduced below in Figure 8 .

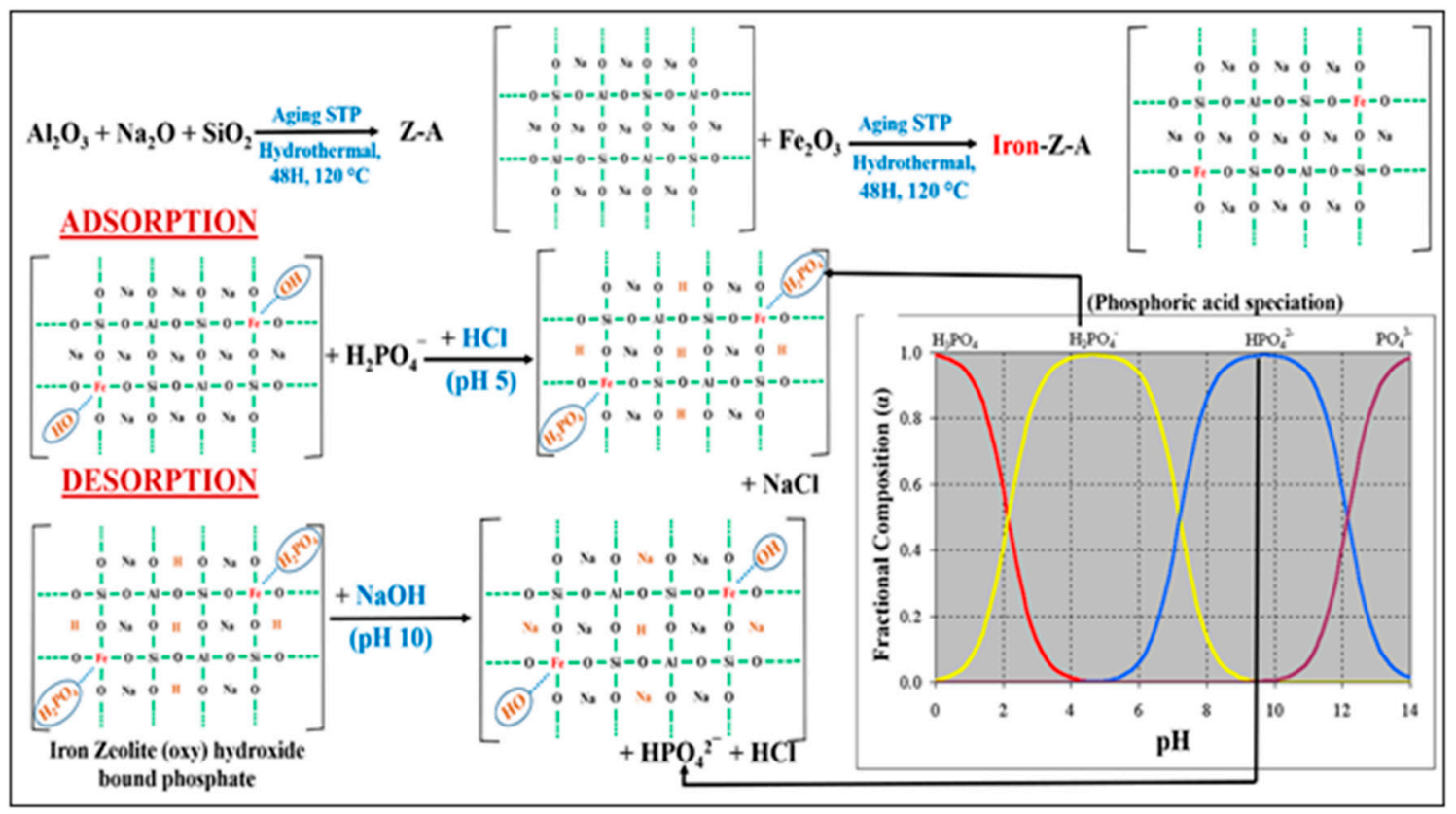

Figure 8. The above figure explains the interacting mechanism behind adsorption and desorption of phosphate on the surface of iron incorporated Iron-Z-A.

\section{Conclusions}

In the present research, an environmental friendly adsorbent, Iron-Z-A, has been practically applied to adsorb as well as desorb phosphate from an aqueous solution by successful incorporation of iron into the skeleton of Z-A in the form of $\mathrm{Fe}^{3+}$, named as Iron-Z-A. The adsorbed phosphate's amount is found to be $156.45 \mathrm{mg}$ by each gram of $\mathrm{Fe}$, whereas each gram of Al contributed to $16.19 \mathrm{mg}$ of phosphate adsorption. The derivatives of phosphate at different $\mathrm{pH}$ of an aqueous solution behaved as a ligand and interacted with $\mathrm{OH}$ radical of iron on zeolite surface, making the chemisorption process of adsorption-desorption of phosphate a reversible one. The adsorption and desorption of phosphate are by the 'ligand exchange principle' exhibited by Fe in the zeolite frame. Langmuir's model of adsorption isotherm, and pseudo-second-order kinetics showed best fitting of the adsorption data.

Supplementary Materials: The following are available online at http://www.mdpi.com/2076-3417/9/22/4897/s1. Table S1: EDS data, Figure S2: Experiment to observe the phosphate adsorption capacity of zeolite-A and iron-zeolite-A from an aqueous solution at $\mathrm{pH} \leq 5$, Figure S3: Optimization of $\mathrm{pH}$ for adsorption of phosphate from an aqueous solution using iron-zeolite-A, Figure S4: Optimization of $\mathrm{pH}$ for desorption of phosphate from an aqueous solution using iron-zeolite-A, Figure S5: Adsorption of phosphate from an aqueous solution using different dosage of the iron-zeolite-A adsorbent at $\mathrm{pH} \leq 5$, Figure S6: Determining reaction order by log plotting.

Author Contributions: Conceptualization by K.S.K. and M.S.; methodology by K.S.K. and M.S.; software support by A.A.; validation by K.S.K. and M.S.; formal analysis by M.S. and S.K.; investigation by M.S. and S.K.; resources by K.S.K.; data curation by M.S. and A.A.; writing — original draft preparation by M.S.; writing-review and editing by M.S. and K.S.K.; visualization by M.S. and S.K.; supervision by K.S.K.; project administration by K.S.K. and S.K.; funding acquisition by K.S.K.

Funding: This project was funded by “Korea Institute of Civil engineering and building Technology" (KICT), Rep. of Korea, grant number 20190151-001. The APC was funded by the same project \# 20190151-001.

Conflicts of Interest: The authors declare no conflict of interest. 


\section{References}

1. Kralchevska, R.P.; Prucek, R.; Kolařík, J.; Tuček, J.; Machala, L.; Filip, J.; Sharma, V.K.; Zbořil, R. Remarkable efficiency of phosphate removal: Ferrate(VI)-induced in situ sorption on core-shell nanoparticles. Water Res. 2016, 103, 83-91. [CrossRef] [PubMed]

2. Cooney, D.O. Adsorption Design for Wastewater Treatment; CRC Press: Boca Raton, FL, USA, 1998; ISBN 978-1-56670-333-8.

3. Applications of Environmental Aquatic Chemistry: A Practical Guide, Third Edition. Available online: https://www.crcpress.com/Applications-of-Environmental-Aquatic-Chemistry-A-Practical-Guide-Third/ Weiner/p/book/9781439853320 (accessed on 1 November 2019).

4. Zhou, J.; Xu, Z.P.; Qiao, S.; Liu, Q.; Xu, Y.; Qian, G. Enhanced removal of triphosphate by MgCaFe-Cl-LDH: Synergism of precipitation with intercalation and surface uptake. J. Hazard. Mater. 2011, 189, 586-594. [CrossRef] [PubMed]

5. Chitrakar, R.; Tezuka, S.; Sonoda, A.; Sakane, K.; Ooi, K.; Hirotsu, T. Selective adsorption of phosphate from seawater and wastewater by amorphous zirconium hydroxide. J. Colloid Interface Sci. 2006, 297, 426-433. [CrossRef] [PubMed]

6. Streat, M.; Hellgardt, K.; Newton, N.L.R. Hydrous ferric oxide as an adsorbent in water treatment: Part 3: Batch and mini-column adsorption of arsenic, phosphorus, fluorine and cadmium ions. Process Saf. Environ. Prot. 2008, 86, 21-30. [CrossRef]

7. Awual, M.R.; Jyo, A.; El-Safty, S.A.; Tamada, M.; Seko, N. A weak-base fibrous anion exchanger effective for rapid phosphate removal from water. J. Hazard. Mater. 2011, 188, 164-171. [CrossRef]

8. Long, F.; Gong, J.-L.; Zeng, G.-M.; Chen, L.; Wang, X.-Y.; Deng, J.-H.; Niu, Q.-Y.; Zhang, H.-Y.; Zhang, X.-R. Removal of phosphate from aqueous solution by magnetic Fe-Zr binary oxide. Chem. Eng. J. 2011, 171, 448-455. [CrossRef]

9. Zeng, L.; Li, X.; Liu, J. Adsorptive removal of phosphate from aqueous solutions using iron oxide tailings. Water Res. 2004, 38, 1318-1326. [CrossRef]

10. Xu, Y.; Dai, Y.; Zhou, J.; Xu, Z.P.; Qian, G.; Lu, G.Q.M. Removal efficiency of arsenate and phosphate from aqueous solution using layered double hydroxide materials: intercalation vs. precipitation. J. Mater. Chem. 2010, 20, 4684-4691. [CrossRef]

11. Hussain, S.; Aziz, H.A.; Isa, M.H.; Ahmad, A.; Van Leeuwen, J.; Zou, L.; Beecham, S.; Umar, M. Orthophosphate removal from domestic wastewater using limestone and granular activated carbon. Desalination 2011, 271, 265-272. [CrossRef]

12. Deliyanni, E.A.; Peleka, E.N.; Lazaridis, N.K. Comparative study of phosphates removal from aqueous solutions by nanocrystalline akaganéite and hybrid surfactant-akaganéite. Sep. Purif. Technol. 2007, 52, 478-486. [CrossRef]

13. Yeoman, S.; Stephenson, T.; Lester, J.N.; Perry, R. The removal of phosphorus during wastewater treatment: A review. Environ. Pollut. 1988, 49, 183-233. [CrossRef]

14. Karageorgiou, K.; Paschalis, M.; Anastassakis, G.N. Removal of phosphate species from solution by adsorption onto calcite used as natural adsorbent. J. Hazard. Mater. 2007, 139, 447-452. [CrossRef] [PubMed]

15. Wei, W.; Du, J.; Li, J.; Yan, M.; Zhu, Q.; Jin, X.; Zhu, X.; Hu, Z.; Tang, Y.; Lu, Y. Construction of robust enzyme nanocapsules for effective organophosphate decontamination, detoxification, and protection. Adv. Mater. Weinheim 2013, 25, 2212-2218. [CrossRef] [PubMed]

16. Samet, Y.; Agengui, L.; Abdelhédi, R. Electrochemical degradation of chlorpyrifos pesticide in aqueous solutions by anodic oxidation at boron-doped diamond electrodes. Chem. Eng. J. 2010, 161, 167-172. [CrossRef]

17. Johnson, B.J.; Malanoski, A.P.; Leska, I.A.; Melde, B.J.; Taft, J.R.; Dinderman, M.A.; Deschamps, J.R. Adsorption of organophosphates from solution by porous organosilicates: Capillary phase-separation. Microporous Mesoporous Mater. 2014, 195, 154-160. [CrossRef]

18. Huo, S.-H.; Yan, X.-P. Metal-organic framework MIL-100(Fe) for the adsorption of malachite green from aqueous solution. J. Mater. Chem. 2012, 22, 7449-7455. [CrossRef]

19. Ahmad, A.; Mohd-Setapar, S.H.; Chuong, C.S.; Khatoon, A.; Wani, W.A.; Kumar, R.; Rafatullah, M. Recent advances in new generation dye removal technologies: novel search for approaches to reprocess wastewater. RSC Adv. 2015, 5, 30801-30818. [CrossRef] 
20. Gupta, V.K.; Gupta, B.; Rastogi, A.; Agarwal, S.; Nayak, A. A comparative investigation on adsorption performances of mesoporous activated carbon prepared from waste rubber tire and activated carbon for a hazardous azo dye-Acid Blue 113. J. Hazard. Mater. 2011, 186, 891-901. [CrossRef]

21. Gupta, V.K.; Gupta, B.; Rastogi, A.; Agarwal, S.; Nayak, A. Pesticides removal from waste water by activated carbon prepared from waste rubber tire. Water Research 2011, 45, 4047-4055. [CrossRef]

22. Wang, X.; Dai, S. A simple method to ordered mesoporous carbons containing nickel nanoparticles. Adsorption 2009, 15, 138-144. [CrossRef]

23. Yen, C.-W.; Lin, M.-L.; Wang, A.; Chen, S.-A.; Chen, J.-M.; Mou, C.-Y. CO Oxidation Catalyzed by Au-Ag Bimetallic Nanoparticles Supported in Mesoporous Silica. J. Phys. Chem. C 2009, 113, 17831-17839. [CrossRef]

24. Lu, S.G.; Bai, S.Q.; Zhu, L.; Shan, H.D. Removal mechanism of phosphate from aqueous solution by fly ash. J. Hazard. Mater. 2009, 161, 95-101. [CrossRef] [PubMed]

25. Babatunde, A.O.; Zhao, Y.Q. Equilibrium and kinetic analysis of phosphorus adsorption from aqueous solution using waste alum sludge. J. Hazard. Mater. 2010, 184, 746-752. [CrossRef] [PubMed]

26. Loganathan, P.; Vigneswaran, S.; Kandasamy, J.; Bolan, N.S. Removal and Recovery of Phosphate From Water Using Sorption. Crit. Rev. Environ. Sci. Technol. 2014, 44, 847-907. [CrossRef]

27. Xue, Y.; Hou, H.; Zhu, S. Characteristics and mechanisms of phosphate adsorption onto basic oxygen furnace slag. J. Hazard. Mater. 2009, 162, 973-980. [CrossRef]

28. Li, Y.; Liu, C.; Luan, Z.; Peng, X.; Zhu, C.; Chen, Z.; Zhang, Z.; Fan, J.; Jia, Z. Phosphate removal from aqueous solutions using raw and activated red mud and fly ash. J. Hazard. Mater. 2006, 137, 374-383. [CrossRef]

29. Mahmudov, R.; Huang, C.P. Selective adsorption of oxyanions on activated carbon exemplified by Filtrasorb 400 (F400). Sep. Purif. Technol. 2011, 77, 294-300. [CrossRef]

30. Wang, J.; Zhang, Y.; Feng, C.; Li, J.; Li, G. Adsorption Capacity for Phosphorus Comparison among Activated Alumina, Silica Sand and Anthracite Coal. J. Water Resour. Prot. 2009, 4, 260-264. [CrossRef]

31. Database of Zeolite Structures. Available online: http://www.iza-structure.org/databases/ (accessed on 1 November 2019).

32. Dana Classification. Available online: http://www.webmineral.com/danaclass.shtml\#.XbsfpJozaM8 (accessed on 1 November 2019).

33. Rashed, M.N.; Palanisamy, P.N. Zeolites and Their Applications; IntechOpen: London, UK, 2018; ISBN 978-1-78923-343-8.

34. Ismail, A.A.; Mohamed, R.M.; Ibrahim, I.A.; Kini, G.; Koopman, B. Synthesis, optimization and characterization of zeolite A and its ion-exchange properties. Colloids Surf. A Physicochem. Eng. Asp. 2010, 366, 80-87. [CrossRef]

35. Jiang, C.; Jia, L.; He, Y.; Zhang, B.; Kirumba, G.; Xie, J. Adsorptive removal of phosphorus from aqueous solution using sponge iron and zeolite. J. Colloid Interface Sci. 2013, 402, 246-252. [CrossRef]

36. Guo, C.; Stabnikov, V.; Kuang, S.; Ivanov, V. The removal of phosphate from wastewater using anoxic reduction of iron ore in the rotating reactor. Biochem. Eng. J. 2009, 46, 223-226. [CrossRef]

37. Chitrakar, R.; Tezuka, S.; Sonoda, A.; Sakane, K.; Ooi, K.; Hirotsu, T. Phosphate adsorption on synthetic goethite and akaganeite. J. Colloid Interface Sci. 2006, 298, 602-608. [CrossRef]

38. Cordray, A. Phosphorus Removal Characteristics on Biogenic Ferrous Iron Oxides. Ph.D. Thesis, Washington State University, Pullman, WA, USA, 2008.

39. Aziz, A.; Kim, S.; Kim, K.S. Fe/ZSM-5 zeolites for organic-pollutant removal in the gas phase: Effect of the iron source and loading. J. Environ. Chem. Eng. 2016, 4, 3033-3040. [CrossRef]

40. Ning, P.; Bart, H.-J.; Li, B.; Lu, X.; Zhang, Y. Phosphate removal from wastewater by model-La(III) zeolite adsorbents. J. Environ. Sci. 2008, 20, 670-674. [CrossRef]

41. Tran, T. Standard Methods For the Examination of Water and Wastewater, 23nd ed.; American Public Health Association: National Harbor, MD, USA, 2017.

42. Synthesis of Iron-loaded Zeolites for Removal of Ammonium and Phosphate from Aqueous Solutions. Available online: http://eeer.org/journal/view.php?number=599 (accessed on 1 November 2019).

43. Vimonses, V.; Lei, S.; Jin, B.; Chow, C.W.K.; Saint, C. Kinetic study and equilibrium isotherm analysis of Congo Red adsorption by clay materials. Chem. Eng. J. 2009, 148, 354-364. [CrossRef]

44. Khamizov, R.K.; Sveshnikova, D.A.; Kucherova, A.E.; Sinyaeva, L.A. Kinetic Models of Batch Sorption in a Limited Volume. Russ. J. Phys. Chem. A 2018, 92, 1782-1789. [CrossRef] 
45. Ho, Y.S.; McKay, G. Pseudo-second order model for sorption processes. Process Biochem. 1999, 34, 451-465. [CrossRef]

46. Ho, Y.S.; McKay, G. The kinetics of sorption of divalent metal ions onto sphagnum moss peat. Water Res. 2000, 34, 735-742. [CrossRef]

47. Anirudhan, T.S.; Senan, P. Adsorption of phosphate ions from water using a novel cellulose-based adsorbent. Chem. Ecol. 2011, 27, 147-164. [CrossRef]

48. Pham, T.-H.; Lee, B.-K.; Kim, J. Improved adsorption properties of a nano zeolite adsorbent toward toxic nitrophenols. Process Saf. Environ. Prot. 2016, 104, 314-322. [CrossRef]

49. Collection of Simulated XRD Powder Patterns for Zeolites Fifth (5th) Revised Edition-5th Edition. Available online: https://www.elsevier.com/books/collection-of-simulated-xrd-powder-patterns-for-zeolitesfifth-5th-revised-edition/treacy/978-0-444-53067-7 (accessed on 1 November 2019).

50. Gupta, N.K.; Gupta, A.; Ramteke, P.; Sahoo, H.; Sengupta, A. Biosorption-a green method for the preconcentration of rare earth elements (REEs) from waste solutions: A review. J. Mol. Liq. 2019, 274, 148-164. [CrossRef]

51. Kanthasamy, R.; Larsen, S.C. Visible light photoreduction of $\mathrm{Cr}(\mathrm{VI})$ in aqueous solution using iron-containing zeolite tubes. Microporous and Mesoporous Materi. 2007, 100, 340-349. [CrossRef]

52. Raman spectroscopy of zeolite A: Influence of silicon/aluminum ratio. J. Physical Chemistry 1988, 92, 354-357. Available online: https://pubs.acs.org/doi/abs/10.1021/j100313a022 (accessed on 1 November 2019). [CrossRef]

53. Kaoua, S.; Krimi, S.; El Jazouli, A.; Hlil, E.K.; de Waal, D. Preparation and characterization of phosphate glasses containing titanium and vanadium. J. Alloy. Compd. 2007, 429, 276-279. [CrossRef]

54. Yadav, A.K.; Singh, P. A review of the structures of oxide glasses by Raman spectroscopy. RSC Adv. 2015, 5, 67583-67609. [CrossRef]

55. Yu, Y.; Murthy, B.N.; Shapter, J.G.; Constantopoulos, K.T.; Voelcker, N.H.; Ellis, A.V. Benzene carboxylic acid derivatized graphene oxide nanosheets on natural zeolites as effective adsorbents for cationic dye removal. J. Hazard. Mater. 2013, 260, 330-338. [CrossRef]

56. Hematite R040024-RRUFF Database: Raman, X-ray, Infrared, and Chemistry. Available online: http: //rruff.info/Hematite/R040024 (accessed on 1 November 2019).

57. Uzunova, E.L.; Mikosch, H. Adsorption of phosphates and phosphoric acid in zeolite clinoptilolite: Electronic structure study. Microporous and Mesoporous Mater. 2016, 232, 119-125. [CrossRef]

(C) 2019 by the authors. Licensee MDPI, Basel, Switzerland. This article is an open access article distributed under the terms and conditions of the Creative Commons Attribution (CC BY) license (http://creativecommons.org/licenses/by/4.0/). 